\title{
What Higher Education Learned About the Accessibility of Online Opportunities During a Pandemic
}

\author{
Sheryl Burgstahler \\ University of Washington
}

\begin{abstract}
The pivot of on-site services and formal and informal learning opportunities to online formats as a result of the COVID-19 pandemic shined a light on access barriers for people with various types of disabilities. This is true in spite of legal obligations for institutions to make their offerings accessible and the existence of well-established principles, guidelines, and practices for making technology, resources, and pedagogy accessible to this group. The author of this article presents a Universal Design in Higher Education (UDHE) Framework as a promising practice that can lead to learning opportunities and student services that are inclusive of all participants.
\end{abstract}

Keywords: disability, ability, diversity, accessibility, universal design, inclusive

\section{INTRODUCTION}

As campuses adapted to the COVID-19 pandemic by moving courses and services online at lightning speeds, not all students gained equitable access to these digital opportunities. An informal review suggests that the overwhelming majority of published articles and online posts that address student "access" issues with respect to online learning primarily discuss the availability of computer systems and Internet connections where typical students live. Not often discussed is how COVID-19 has shined a light on additional access challenges for students with various types of disabilities as they attempt to engage in online courses and services. This article presents a framework for guiding all aspects of a postsecondary institution's offerings - the technology they use, the formal and informal courses they teach, the services they deliver, and the physical spaces they create - to ensure that they are welcoming to, accessible to, and inclusive of all students, including those with disabilities, as well as provides guidelines for institutionalization of inclusive practices.

Long before the pandemic, postsecondary students increasingly interacted with technology in education activities. They access Learning Management Systems (LMSs), websites, and other IT in myriad ways, including those described below.

- Students use tablets, smart phones, and other hand-held devices that vary in screen size and use multiple user interfaces such as keyboards and touch screens.

- Individuals in quiet spaces, including those where others are sleeping, rely on captions to access content in video presentations, as do those who are located in noisy environments, are English language learners, or are deaf or hard of hearing. 
- Students who are blind use screen reader technology that synthesizes speech to read aloud digital text. Students with reading-related disabilities or who are English language learners employ similar technology so that they can simultaneously read text and hear it spoken.

- Individuals with low vision use software that enlarges font sizes and screen images on the screen.

- Speech recognition, head pointers, mouth sticks, eye-gaze tracking systems, alternative keyboards, and other assistive technologies make computer use possible for individuals without functional use of their hands or who have limited fine motor skills.

Literally thousands of hardware and software configurations allow individuals with a wide variety of disabilities to effectively use mainstream technologies. Full access, however, requires that mainstream technologies apply standards that include the World Wide Web Consortium's Web Content Accessibility Guidelines (WCAG, 2018). Modern LMSs and other technologies generally offer multimodal representation of information, interactive activities, immersive learning environments, and personalized learning. However, those who develop and procure these technologies often target the "average" student or employee rather than trying to provide access to the most users possible, erecting barriers to some people with disabilities. For example, it is helpful for blind readers to know whether the text they are reading with screen readers are headings or subheadings, paragraphs, elements in tables, or list items. While most computer users access this information using sight, blind students gain this useful information from their screen readers as long as the content source has been coded using the built-in formatting capabilities of a word processor, hypertext markup language (HTML), or other application used to present the content. Without such coding, document text may be read by the screen reader as a stream of text that is difficult to parse.

Legal issues surround the use of technologies and pedagogical practices for the delivery of online services and formal and informal learning. Postsecondary institutions are covered entities under Section 504 of the Rehabilitation Act of 1973 as well as the Americans with Disabilities Act of 1990 and its 2008 Amendments. These laws mandate that no otherwise qualified person with a disability be excluded from participation in, be denied the benefits of, or be subjected to discrimination with respect to participation in these opportunities. Hundreds of civil rights complaints have been brought to the US Department of Education Office for Civil Rights and the US Department of Justice regarding the inaccessibility of technology used to support offerings at postsecondary institutions. Schools who are the recipients of these complaints must reach resolution agreements with the federal government. These resolutions make clear that using inaccessible websites, multimedia, documents, curricula, videos, online learning tools, and other technologies may violate the civil rights of individuals with disabilities trying to use these products and environments (EDUCAUSE, 2015; Office of Civil Rights, 2016). Campuses who reach these resolutions must follow strict guidance to correct the inaccessible IT findings, including proactively remediating inaccessible websites, documents, and videos used in offering services and online learning.

\section{FRAMEWORKS FOR ADDRESSING ACCESS ISSUES}

It is estimated that more than $10 \%$ of postsecondary students in the United States have disabilities; however, the majority of these students do not register with the disability services office on their campuses. Some of the reasons students report for not sharing information about their disabilities are fears of potential discrimination on the part of instructors, anticipation that they will not need accommodations, and expectations that available accommodations will not meet their needs. Most reported and unreported disabilities are not obvious; such conditions include autism spectrum disorders, learning disabilities, attention deficits, hyperactivity, mental illness, and health impairments.

An accommodation framework for addressing the inaccessible design of physical spaces, technology, courses, and services is deeply rooted in the culture of most postsecondary institutions. This approach takes a "medical" or "deficit" view of disability, whereby professionals review individuals' medical conditions and functional deficits and prescribe adjustments that allow them to engage in offerings that are not designed to be accessible to them. Accommodations include providing extra time to complete tests or 
assignments, remediating inaccessible documents, captioning videos, adjusting or replacing an assignment, and offering another method for accessing course content when a technology tool is inaccessible for a specific student enrolled in a class.

The accommodations approach for making school offerings accessible to students with disabilities has been criticized by people with disabilities and their allies for reasons that include those that follow.

- The process of obtaining accommodations marginalizes students with disabilities by requiring a separate process for them to gain access to materials the institution routinely offers to other students without making special requests (e.g., remediating content within course documents presented in formats that are inaccessible to students with some types of disabilities).

- An accommodation process often results in a student receiving content and experiences at a time later than that of other students.

- Accommodations are offered only to students with disabilities who present documentation and request them, even though students with undisclosed disabilities and others might benefit from them as well (e.g., English language learners benefit from captions, but are not eligible for reasonable accommodations unless they have disabilities).

- The process focuses on the perceived "deficit" of an individual while little attention is given to remediating deficits in the designs of educational products and environments (e.g., requiring faculty to routinely use accessibly-designed documents and captioned videos as a best practice in teaching; Burgstahler, 2020).

Thus the "retrofit" approach of accommodations does little to break down barriers to future students with disabilities who engage in a course or use a service. Some refer to such routine inaccessibility as "structural ableism." In the book Academic Ableism: Disability and Higher Education, Domage states the following:

There is a structural ableism to the university: a way of repeatedly rewarding bodies and minds and forms of communication and sociality that are the right (constrained) shape. But there is also an explicit disablism that denigrates specific bodies and minds and forms of communication and sociality. The retrofit is one way in which we address structural ableism (for instance an inaccessible space) that means that simply highlight and accentuate and invite disablism - for instance, single out the body that needs to ask for access. (2017, p. 70)

Proponents of proactive, inclusive design practices encourage institutions to accept their role in creating systemic barriers and take steps to reduce them. Universal design (UD) frameworks take into consideration wide variations in human characteristics, including abilities, during design processes. The following paragraphs share this approach, which is consistent with social, political, and related models of disability that prioritize efforts to create products and environments that are "born accessible."

\section{UNIVERSAL DESIGN IN HIGHER EDUCATION: DEFINITION, PRINCIPLES, AND PRACTICES}

There is no shortage of proactive design approaches. Among them are design for all, accessible design, inclusive design, usable design, ability-based design, user-centered design, design for user empowerment, barrier free design, and UD (Burgstahler, 2020). Although all contribute to the field, UD is an excellent choice to embrace in higher education because it has a long history of research and practice and can be used to maximize the benefit of any product and environment, including digital learning technology and pedagogy, for everyone. The Centre for Excellence in Universal Design (n.d.) in Dublin summarizes characteristics of UD and addresses misconceptions about it by asserting these statements:

- UD is much more than just a new design trend.

- UD strives to improve an original design concept by making it more inclusive. 
- UD benefits are not limited to older people and people with disabilities.

- UD is not about "one size fits all."

- UD is not a synonym for compliance with accessible design standards.

- UD should be integrated throughout the design process.

- Universally designed products can have high aesthetic value.

- A universally designed product is the goal; UD is the process.

- UD does not aim to replace the design of products targeted at specific markets.

- UD can be undertaken by any designer, not just by specialists. (p. 1)

Three sets of principles contribute to a comprehensive UD in Higher Education (UDHE) Framework that addresses all postsecondary offerings - the seven principles of UD, the four principles of the Web Content Accessibility Guidelines (WCAG), and the three principles of Universal Design for Learning (UDL). Applying the three sets of principles requires that a broad spectrum of abilities and other characteristics of potential students be considered when developing educational products and environments, rather than simply designing for the average student and relying on accommodations when it is discovered that a product or environment is not accessible to a specific student.

UD is defined by the Center for Universal Design (n.d.) as "the design of products and environments to be usable by all people, to the greatest extent possible, without the need for adaptation or specialized design." Resulting practices go beyond the low bar of "ADA compliance" to create opportunities that fully engage individuals who have disabilities, are English language learners, represent various racial and ethnic groups, and are members of other marginalized groups. Below are the principles for the UD of any product or environment:

1. Equitable use: The design is useful and marketable to people with diverse abilities.

2. Flexibility in use: The design accommodates a wide range of individual preferences and abilities.

3. Simple and intuitive use: Use of the design is easy to understand, regardless of the user's experience, knowledge, language skills, or current concentration level.

4. Perceptible information: The design communicates necessary information effectively to the user, regardless of ambient conditions or the user's sensory abilities.

5. Tolerance for error: The design minimizes hazards and the adverse consequences of accidental or unintended actions.

6. Low physical effort: The design can be used efficiently, comfortably, and with a minimum of fatigue.

7. Size and space for approach and use: Appropriate size and space is provided for approach, reach, manipulation, and use regardless of the user's body size, posture, or mobility. (Story, Mueller, \& Mace, 1998, pp. 34-35)

Although they offer general guidance in designing any product or environment, these principles were first applied to the design of physical spaces and commercial products. They are particularly useful in designing classrooms, makerspaces, engineering labs, recreation centers, and other physical spaces in higher education. They have also been applied to the design of hardware and software, instruction, and student services (Burgstahler, 2020).

More specialized UD-inspired principles have emerged to specifically address the design of IT. Technology barriers for some students include document and web content that is not provided in a textbased format and structured to optimize access for individuals using screen readers. Potential barriers to digital tools and content can be avoided by applying WCAG, originally published in 1999. While they were developed for web-based technologies, WCAG principles, guidelines, and practices provide guidance for the UD of digital media, software, and other technologies as well (W3C, 2013). These Guidelines require that technology design adhere to four guiding principles:

1. Perceivable: Users must be able to perceive the content, regardless of the device or configuration they're using. 
2. Operable: Users must be able to operate the controls, buttons, sliders, menus, etc., regardless of the device they're using.

3. Understandable: Users must be able to understand the content and interface.

4. Robust: Content must be coded in compliance with relevant coding standards in order to ensure its accurately and meaningfully interpreted by devices, browsers, and assistive technologies.

Research studies and practitioner reports have routinely found that learners vary greatly in their abilities and responses to different curriculum and instruction. The most common UD-inspired principles for addressing these variations when designing learning materials and activities are those developed by the Center for Applied Special Technology (CAST). Practicing UDL requires that instructors offer students multiple means for engagement, representation, and action and expression throughout their course as presented below:

1. Engagement: For purposeful, motivated learners, stimulate interest and motivation for learning.

2. Representation: For resourceful, knowledgeable learners, present information and content in different ways.

3. Action and expression: For strategic, goal-directed learners, differentiate the ways that students can express what they know. (CAST, 2018)

Rather than memorize the total of fourteen basic principles that underpin UDHE, practitioners can address most issues regarding accessibility and inclusion for all students, including those with disabilities, by

- Providing multiple ways for students to learn, demonstrate what they have learned, and engage.

- Ensuring that all technologies, facilities, services, resources, and strategies are accessible to individuals with a wide variety of disabilities. (Burgstahler, 2020)

Although the need is minimized with the UDHE approach, reasonable accommodations continue to be necessary to ensure full access and engagement for some individuals. For example, a student with a learning disability in a universally-designed learning activity may be provided with extra time on an examination as a reasonable accommodation; a student who is deaf may be provided with a sign language interpreter if requested.

Evidence-based practices have been established for all three sets of principles that underpin the UDHE Framework. See Table 1 for a list of examples for all fourteen principles (Burgstahler, 2020, p. 95).

TABLE 1

EXAMPLES OF UDHE PRINCIPLES APPLIED TO HIGHER EDUCATION PRACTICES

\begin{tabular}{ll}
\hline UDHE Principle & Example of UDHE Practice \\
\hline UD 1. Equitable use & $\begin{array}{l}\text { Career services. Job postings are in formats accessible to } \\
\text { people with a great variety of abilities, disabilities, ages, } \\
\text { racial/ethnic backgrounds, and technologies. }\end{array}$ \\
\hline UD 2. Flexibility in use & $\begin{array}{l}\text { Campus museum. An exhibit design allows a visitor to } \\
\text { choose to read or listen to descriptions of the contents of } \\
\text { display cases. }\end{array}$ \\
\hline UD 3. Simple and intuitive & $\begin{array}{l}\text { Assessment. Testing is conducted in a predictable, } \\
\text { straightforward manner. }\end{array}$ \\
\hline UD 4. Perceptible information & $\begin{array}{l}\text { Dormitory. An emergency alarm system has visual, aural, } \\
\text { and kinesthetic characteristics. }\end{array}$ \\
\hline UD 5. Tolerance for error & $\begin{array}{l}\text { Instructional software. An application provides guidance } \\
\text { when a student makes an inappropriate selection. }\end{array}$ \\
\hline UD 6. Low physical effort & $\begin{array}{l}\text { Curriculum. Software includes on-screen control buttons } \\
\text { that are large enough for students with limited fine motor } \\
\text { skills to select. }\end{array}$ \\
\hline
\end{tabular}




\begin{tabular}{|c|c|}
\hline $\begin{array}{l}\text { UD 7. Size and space for approach and } \\
\text { use }\end{array}$ & $\begin{array}{l}\text { Science lab. An adjustable table and flexible work area is } \\
\text { usable by students who are right- or left-handed and have } \\
\text { a wide range of physical characteristics. }\end{array}$ \\
\hline UDL 1. Multiple means of engagement & $\begin{array}{l}\text { Courses. Multiple examples ensure relevance to a diverse } \\
\text { student group. }\end{array}$ \\
\hline UDL 2. Multiple means of representation & $\begin{array}{l}\text { Promote services. Multiple forms of accessibly designed } \\
\text { media are used to communicate services provided. }\end{array}$ \\
\hline $\begin{array}{l}\text { UDL3. Multiple means of action and } \\
\text { expression }\end{array}$ & $\begin{array}{l}\text { Course project. An assigned project optimizes individual } \\
\text { choice and autonomy. }\end{array}$ \\
\hline WCAG 1. Perceivable & $\begin{array}{l}\text { Student service website. A person who is blind and using a } \\
\text { screen reader can access the content in images because } \\
\text { text descriptions are provided. }\end{array}$ \\
\hline WCAG 2. Operable & $\begin{array}{l}\text { Learning management system (LMS). A person who } \\
\text { cannot operate a mouse can navigate all content and } \\
\text { operate all functions by using a keyboard (or device that } \\
\text { emulates a keyboard) alone. }\end{array}$ \\
\hline WCAG 3. Understandable & $\begin{array}{l}\text { Instructional materials. Definitions are provided for } \\
\text { unusual words, phrases, idioms, and abbreviations. }\end{array}$ \\
\hline WCAG 4. Robust & $\begin{array}{l}\text { Application forms. Electronic forms can be completed } \\
\text { using a wide range of devices, including assistive } \\
\text { technologies. }\end{array}$ \\
\hline
\end{tabular}

\section{UDHE APPLIED TO ONLINE LEARNING AND SERVICES}

Routinely applying UDHE principles campus-wide can lead to a paradigm shift from designing for some students to designing for all of them. In the case of online offerings, to get started, it is important for educators to assume that students in future offerings will have a wide variety of abilities and other characteristics, be aware of the wide range of mainstream and assistive technologies students use, understand challenges individuals with disabilities often face when accessing materials and engaging in activities, and employ design approaches that result in accessible, usable, and inclusive learning opportunities. Even as research pushes the boundaries of current technologies and practices, the basic principles for UD, UDL, and WCAG stand the test of time; only specific practices may need to be adjusted over time. Some UDHE practices for designing accessible online courses offered by researchers and practitioners include those listed below:

- Communication: Provide options for communicating with the instructor and other students and, when possible, allow individual students to make choices in this regard.

- Learning and demonstrating what is learned: Provide options for students to learn and to demonstrate what they have learned.

- Reading materials: It is relatively easy to make content accessible when you enter it directly into the pages of a learning management system. If you want to link to a document, avoid creating PDF documents, unless you choose to invest significant time in learning to make them accessible; in contrast Microsoft Word and PowerPoint are more easily made accessible. In content pages and documents, structure headings using the formatting options in the application. Use large, sans serif fonts, uncluttered pages, and plain backgrounds when presenting content.

- Hyperlinks and images: Provide descriptive text for hyperlink text and provide alternative text for images.

- Videos: Caption videos and ensure that content in videos can be understood by someone who cannot see visual elements.

- Course content: Make instructions and expectations clear. Use plain language, spell out acronyms, and define jargon. 
- Technology: Address a wide range of technology skills by minimizing the number of different digital tools you use and offering resources to help students gain the skills they need to fully engage in the course. Make sure that the tools you choose to use are accessible to screen readers and can be operated with the keyboard alone. (AccessCyberlearning 2.0, 2019; Aluri, August 25, 2020; Burgstahler \& Thompson, 2019).

Experiences in online learning shared by students with disabilities have been shared in the literature (e.g., Catalano, 2014; Roberts, Crittenden, \& Crittenden, 2011; Fichten, Ferraro, Asuncion, Chwojka, Barile, Nguyen, Klomp, \& Wolforth, 2009; Kumar \& Wideman, 2014; Rao \& Tanners, 2011). In a meeting of practitioners and researchers exploring issues surrounding how future online learning opportunities can be made more inclusive, current and past postsecondary students with disabilities were invited to report the difficulties they faced in engaging in online learning, both with barriers associated with the technology and teaching practices used. When asked how they could make online learning more inclusive, panelists suggested these tips for instructors:

- Offer multiple ways to gain knowledge, such as through a video paired with printed materials.

- Provide all materials that are accessible to students with disabilities at the same time they are provided to other students.

- Caption videos to benefit a wide variety of students, including English language learners, those in noisy (e.g., airports) or noiseless (e.g., libraries, buses) environments, individuals who want to search content, in addition to people with hearing and learning disabilities.

- Design videos to include audio content for visual elements of a video whenever possible (e.g., have the credits and other information at the end of a video spoken by the narrator) to maximize access for individuals who are blind or otherwise cannot see the screen. Consider adding audio description to describe other key elements of the content presented visually.

- Provide text descriptions for all visuals.

- Use accessibility designed documents (e.g., PDFs, PowerPoint slides).

- Engage with students in multiple ways.

- In online discussions, to help students, especially those with learning and communications challenges, provide a specific focus to each discussion question, provide guidance in how to answer the question, engage in and guide the discussion, and summarize the group of responses. (AccessCyberlearning 2.0, 2019)

This author's engagement with students and instructors is consisted with publications that suggest that the accessibility of learning environments is not routinely addressed as courses are being designed and delivered. Some online instructors and designers are not aware of laws that require that the courses they create need to be accessible to students with disabilities; some feel that accommodations provided by a disability services office are adequate to address any student accessibility issues that come up; some consider it unreasonable that they apply accessible design practices when they develop a course; some need training and support to make this happen; others feel a central resource should caption all videos and remediate inaccessible documents upon request; and do not plan to change their inaccessible design practices until campus leaders make such responsibilities clear.

\section{BUILDING A MODEL FOR AN INCLUSIVE CAMPUS}

The UDHE Framework holds promise to guide diversity, equity, and inclusion initiatives in an academic department, formal or informal online learning program, student service unit, other campus unit, or campus-wide. For example, the author of this article developed a model for implementation that resulted from undertaking an exercise similar to that commonly used in grant writing - the development of a "logic model," which is a graphic depiction of relationships between various issues included in a grant proposal. The resulting Inclusive Campus Model, as presented in Figure 1, includes campus vision, goals, objectives, activities, outputs, outcomes, impacts, and other relevant aspects of a project or initiative. 


\section{FIGURE 1 \\ INCLUSIVE CAMPUS MODEL UNDERPINNED BY THE UDHE FRAMEWORK}

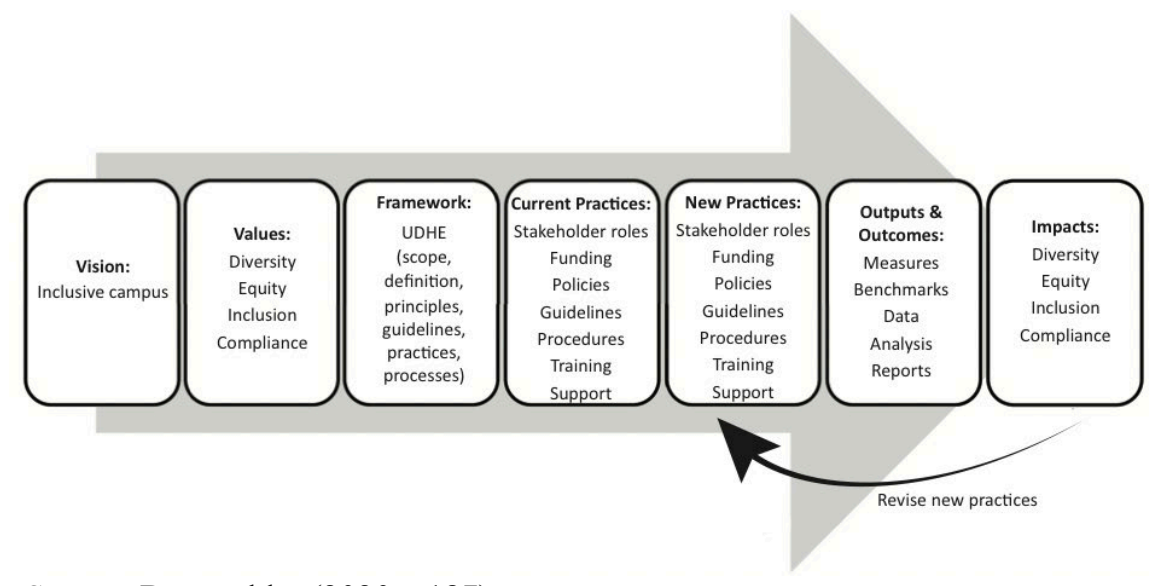

Source: Burgstahler (2020, p187)

To tailor the Inclusive Campus Model or a similar approach to a campus, leaders can flesh out its components with answers to the following questions.

- Vision: What is our vision for an inclusive campus?

- Values: What campus values (e.g., diversity, equity, inclusion, compliance) are most relevant to making our campus more inclusive?

- Framework: What framework (e.g., the UDHE Framework that includes the scope, definition, principles, guidelines, practices, and processes) reflects our campus vision and values and can be fleshed out to guide work toward making our campus more inclusive?

- Current Practices: What are our current practices with respect to stakeholder roles, funding, policies, guidelines, procedures, training, support, and other relevant issues?

- New Practices: What existing practices should we modify and which new practices should we develop to be more consistent with our vision, values, and Framework?

- Outputs and Outcomes: What measures should be identified, what benchmarks should be set, what data should be collected and analyzed, and what reports should be made?

- Impact: What evidence suggests a positive impact of our efforts with respect to a more inclusive campus with respect to our vision and values? (Burgstahler, 2020, p. 189)

\section{IMPLEMENTATION}

Examples of implementing one of the three components of UDHE-UDL in learning applications, UD to facility design, and WCAG in the design of IT-on a campus can be found at schools world-wide; however, it is rare to find cases where all three of the UDHE sets of principles are considered for all aspects of an institutional offerings or even within a single unit. One example of taking a more comprehensive approach can be found in the Accessible Technology Services unit at the University of Washington (UW), that the author of this article directs. Roughly speaking, the model employed by ATS's IT Accessibility Team, with input from the campus-wide IT Accessibility Task Force, is summarized as follows.

- Vision and values: In support of a more inclusive campus, the Team's shared vision is that all IT procured, developed, and used at the UW is accessible to students, faculty, staff, and visitors, including those with disabilities. All efforts are consistent with UW values of diversity, equity, inclusion, and compliance.

- Framework: A UDHE Framework is applied. The basic definition of UD and its principles and guidelines inform the overall design of all IT, including physical spaces that support IT use; 
WCAG principles and guidelines inform the design of hardware and software; in addition, UDL principles and guidelines inform the design of online learning.

- Current and New Practices: For planning purposes, the Team developed three columns on a spreadsheet to itemize practices - relevant to stakeholder roles, funding, policies, guidelines, procedures, training, and support - that were (1) currently in place, (2) new desired UDHEaligned practices, and (3) necessary for bridging the gap between the two.

- Outputs and Outcomes: A mix of measures, benchmarks, and reports were adopted and continue to be used to document progress and refine practices.

- Impacts: Ongoing analysis of outputs and outcomes suggests increased alignment with the UW vision and values with respect to a more inclusive campus. (Burgstahler, 2020)

Promoting these types of efforts in all campus offerings, including online learning in formal and informal settings, benefit when campus leaders send a clear message that their vision of diversity, equity, and inclusion embraces the full engagement of students with disabilities and encourage the routine application of UDHE practices campus-wide. A campus leader could take part in any of the following practices:

- Insist that disability be considered in all diversity, equity, and inclusion initiatives.

- Require the procurement, development, and use of accessible technologies.

- Assign responsibilities of specific stakeholders regarding the proactive, accessible design and delivery of courses and services (e.g., faculty) and campus units (e.g., the central information technology unit, procurement) as well as the provision accommodations for specific individuals for whom a course or service is not accessible (e.g., disability services).

- Ensure the offering of professional development tailored to specific stakeholder groups such as instructors, course designers, and student services staff.

Researchers who routinely include individuals with disabilities and consider accessibility issues within design, development, and evaluation processes can also contribute to the goal of a future where more learning and other opportunities are accessible to and inclusive of all students and employees, including those with disabilities. Specifically, the field of online learning would benefit from more research studies in learning sciences and technology design that specifically address the unique needs of individuals who have diverse abilities. In an exploratory research study, it was recommended that researchers in these fields

- become familiar with the UD, UDL, and WCAG principles, guidelines, and practices that apply to the design of accessible and inclusive online learning tools and pedagogy;

- invite someone with IT accessibility knowledge to be a member of research teams;

- ensure project staff are trained on basic UD, UDL, and WCAG principles as well as relevant standards-compliant coding practices;

- establish internal policies and guidelines for accessibility within their projects, and, if relevant, their departments or institution;

- consider a broad range of learning styles and disability types during all phases of conceiving and designing a project or product;

- analyze the experiences of participants with different types of disabilities along with other demographic groups when reporting research results; and

- when reporting limitations of studies, include accessibility limitations. (Burgstahler \& Thompson, 2019)

\section{CONCLUSION}

What can be learned as massive numbers of postsecondary services and formal and informal learning opportunities quickly moved to online formats as a result of the COVID-19 outbreak? First, even with civil rights legislation, accommodations provided by disability services units, and readily available principles and evidence-based practices for the accessible design of digital technology and pedagogy, the pandemic revealed significant barriers to some students with disabilities attempting to fully benefit from online 
opportunities. The pandemic also shed light on how an accommodations-only approach cannot ensure equitable and inclusive access and engagement for every student. Fleshing out a UDHE Framework into an inclusive model offers a promising practice for ensuring campus offerings are accessible to and inclusive of a diverse student body and guides an institution in meeting its civil rights obligations and goals for its diversity, equity, and inclusion initiatives. Such an approach can contribute to achieving a "new normal" post-pandemic that reflects a paradigm shift from designing opportunities for some students to designing them for all students. Achieving such a transformation will likely require top-down, bottom-up, and middleout leadership and practices. Others who can play a role are advocates who have not lost their capacity for outrage when marginalized students are treated unfairly, yet are patient enough to work through the slow process of systemic change.

\section{ACKNOWLEDGEMENTS}

Some of the content of this chapter is based on work funded in part by the National Science Foundation (Grant numbers CNS 1539179, DRL 1906147, and EEC 1028725). Any questions, findings, and conclusions or recommendations expressed in this publication are those of the author and do not necessarily reflect the views of the NSF.

\section{REFERENCES}

AccessCyberlearning 2.0. (2019). Capacity building institute. Seattle: DO-IT, University of Washington. Retrieved from https://uw.edu/doit/accesscyberlearning-20-capacity-building-institute-2019

Aluri, L. (2020, August 25). Digital accessibility in the age of COVID-19. American Association of People with Disabilities. Retrieved from https://www.aapd.com/digital-accessibility-covid-19/

Americans with Disabilities Act Amendments Act of 2008. 42 U.S.C.A. § 12102 note. (2011).

Burgstahler, S. (2020). Creating inclusive learning opportunities: A universal design toolkit. Harvard Education Press.

Burgstahler, S., \& Thompson, T. (Eds). (2019). Designing accessible cyberlearning: Current state and pathway forward. Seattle: University of Washington. Retrieved from https://www.washington.edu/doit/accessible-cyberlearning-community-report

Catalano, A. (2014). Improving distance education for students with special needs: A qualitative study of students' experiences with an online library research course. Journal of Library \& Information Services in Distance Learning, 8(1-2), 17-31.

Center for Applied Special Technology (CAST). (2018). Universal design for learning guidelines version 2.2. Retrieved from udlguidelines.cast.org/more/research-evidence

Center for Universal Design in Education. (n.d.). Retrieved from http:/uw.edu/doit/cude

Center for Universal Design. (n.d.). History of universal design. Retrieved from https://projects.ncsu.edu/design/cud/about_ud/udhistory.htm

Dolmage, J.T. (2017). The retrofit. In Academic ableism: Disability and higher education. University of Michigan Press. Retrieved from https://www.jstor.org/stable/j.ctvr33d50.5

EDUCAUSE. (2015). IT accessibility risk statements and evidence. Washington DC: Author. Retrieved from https://library.educause.edu/resources/2015/7/it-accessibility-risk-statements-and-evidence

Fichten, C.S., Ferraro, V., Asuncion, J.V., Chwojka, C., Barile, M., Nguyen, M.N., . . W Wolforth, J. (2009). Disabilities and e-learning problems and solutions: An exploratory study. Educational Technology and Society, 12(4), 241-256.

Kumar, K.L., \& Wideman, M. (2014). Accessible by design: Applying UDL principles in a first year undergraduate course. Canadian Journal of Higher Education, 44(1), 125-147. Retrieved from https://files.eric.ed.gov/fulltext/EJ1028772.pdf

Office for Civil Rights. (2016). Securing equal educational opportunity: Report to the president and secretary of education (p.32). Washington, DC: U.S. Department of Education. Retrieved from 
https://www2.ed.gov/about/reports/annual/ocr/report-to-president-and-secretary-of-education2016.pdf

Rao, K., \& Tanners, A. (2011). Curb cuts in cyberspace: Universal instructional design for online courses. Journal of Postsecondary Education and Disability, 24(3), 211-229. Retrieved from https://files.eric.ed.gov/fulltext/EJ966125.pdf

Roberts, J.B., Crittenden, L.A., \& Crittenden, J.C. (2011). Students with disabilities and online learning: A cross-institutional study of perceived satisfaction with accessibility compliance and services. The Internet and Higher Education, 14(4), 242-250.

Section 504 of the Rehabilitation Act of 1973, as amended. 29 U.S.C. § 794.

Story, M.F., Mueller, J.L., \& Mace, R.L. (1998). The principles of universal design and their application. In M.F. Story, M.L. Mueller, \& R.L. Mace (Eds.), The universal design file: Designing for people of all ages and abilities (pp. 32-36). Raleigh, NC: Center for Universal Design. Retrieved from http://www.ncsu.edu/ncsu/design/cud/pubs_p/docs/udffile/chap_3.pdf

The Centre for Excellence in Universal Design. (n.d.). 10 things to know about UD. Dublin: National Disability Authority. Retrieved from universaldesign.ie/what-is-universal-design/the-10-thingsto-know-about-ud/10-things-to-know-about-ud.html

World Wide Web Consortium. (2013). Guidance on applying WCAG 2.0 to non-web information and communications technologies. Retrieved from https://www.w3.org/TR/wcag2ict/

World Wide Web Consortium. (2018). Web content accessibility guidelines, 2.1. Retrieved from http://www.w3.org/TR/wcag21/ 